\title{
Abstract
}

This article utilizes the concepts of biographical disruption and biographical flow to expand understandings of how a therapeutic engagement with the rural landscape may change over time for individual stroke survivors. In doing so, it explores how the rural landscape can be experienced as both a therapeutic and a non-therapeutic landscape. The paper draws on in-depth interviews with nineteen stroke survivors living in rural areas in the Northern Netherlands. Because of the cognitively and physically disabling changes that can occur as a result of stroke, interviewees' stories revealed complex and often contradictory experiences of the rural, post-stroke, that varied significantly from their pre-stroke experiences. Our findings demonstrate that the rural holds potential to function as a therapeutic landscape for stroke survivors, especially through its enabling natural and social characteristics. However, the different physical, social, natural, and healthcare aspects of the rural can also disrupt stroke survivors' individual biographies and their sense of self. The privileging of place in these biographies may provide important insights that can help improve the practice of stroke care. It also leads us to conclude that the concepts of biographical flow and disruption, though useful, need to take into account the influence of the wider (spatial) context. We thus coin the terms bio-geo-graphical flow and bio-geo-graphical disruption, and suggest that these may more accurately reflect the spatio-temporal disruptions and flows experienced by stroke survivors in the post-stroke period.

23 Keywords: therapeutic landscape; stroke survivors; biographical disruption and biographical flow;

24 qualitative methods; rural areas; the Netherlands 
The natural environment has often been framed as health promoting, especially for people who experience physical or mental ill-health (Hartig and Staats, 2006; Kaplan, 1995; Ulrich, 1984). One way in which researchers have sought to understand the inter-relationships between people, place and health is through the concept of therapeutic landscapes. First posited by Gesler (1992: 743) the concept focuses on "how the healing process works itself out in places (or situations, locales, settings and milieus)". Since Gesler's (1992) initial work, numerous geographers, particularly those working in the sub-disciplinary field of health, have drawn on his ideas to tease out the therapeutic effects of a wide range of landscapes - from landscapes that are highly individual and unique to those that are more ubiquitous such as built and urban landscape (e.g. Curtis et al, 2013; Masuda and Crabtree, 2010; Williams, 2010). Importantly for this article, significant weight has been attached to understanding the potential healing, or health enhancement effects, of the natural landscape. A growing body of knowledge within both health geography and environmental psychology highlights the positive and restorative effects of being in, or engaging with, the natural environment. Work here, for example, has considered the relational health effects of natural landscapes with varying groups of people ranging from: young adults; older people; those seeking respite; the terminally ill; those in recovery from either mental or physical ill-health; and family care-givers (e.g.Conradson, 2005; Hartig and Staats, 2006; Kaplan, 1995; Milligan et al, 2004; Moore et al, 2013; Ulrich, 1983, 1984; Willis, 2009; Wood et al, 2013). Research in this field points to a range of health promotion and wellbeing benefits from engagement with natural and healing environments including: an increased sense of belonging and purpose (Williams, 2002); the moderation of stress and anxiety (Korpela et al, 2008); increased social interaction and the promotion of social capital (Carpiano, 2006; Cattell et al, 2008); and the instigation of social and environmental interventions designed to promote and support healthy behaviors (Milligan et al, 2004; Milligan et al, 2015). In a review of this broad range of literature, Duff (2012) noted that one of its most salient themes is that there is a need to further 51 understand the social, affective and material resources of enabling places that contribute to the promotion of wellbeing. 
54 different people can experience the same landscapes. Hence, what may prove a therapeutic or 55 salutogenic experience for one individual, can give rise to anxiety, uncertainty or fear in others (Milligan and Bingley, 2007). The emphasis here, however, has been on differences in experiences between individuals, highlighting how some places can both 'hurt' and 'heal' at the same time (Wakefield and McMullan, 2005: 300). Willis (2009) also raised the important question of whether the therapeutic landscape is experienced as palliative (i.e. where therapeutic benefits are experienced only when in or on the landscape but not beyond), or whether there are longer-term healing or health enhancement effects. What is largely absent in the literature then, is an understanding of the temporal dimension of therapeutic landscape effects; that is, how the relational and the therapeutic engagement with landscape can change for the individual at different points in their lives.

\section{Stroke and disability}

In this article, we address the biographical stories of enabling and disabling aspects of the rural environment by drawing on the specific experiences of stroke survivors living in rural areas in the Netherlands. A stroke is a sudden death of brain cells due to a lack of oxygen, caused by blockage of blood flow, or by rupture of an artery to the brain. Most stroke survivors continue their lives with lasting physical, cognitive and/or emotional impairments which can include paralysis, loss of balance, and coordination, loss of concentration, memory, understanding, speech, and reading and writing skills (BHF, 2014). Such lasting impairments are likely to change the ways in which stroke survivors perceive and engage with their environment.

In the Netherlands, $6.1 \%$ of people aged 50 and over experience a stroke and survive (CBS, 2014); many of these survivors live in rural areas. Following a stroke, most are admitted to an acute stroke unit in hospital. They are then either discharged back to their own home, sent to a specialized 
depends on the impact of the stroke on the individual, their age and their prospects for recovery. Our study focused on stroke survivors with moderate to severe disabilities who worked on their recovery in a rehabilitation stroke unit before being discharged to their home. Within the rehabilitation stroke unit, survivors work on their recovery with the support of a specialized multi-disciplinary team of physiatrists, physical therapists, occupational therapists, nutritionists, speech therapists, psychologists, social workers, and nursing staff.

When studying disability in rehabilitation medicine, the International Classification of Functioning, Disability and Health (ICF) is widely used, as it provides a coherent view of health from a biological, individual and social perspective (Stucki et al, 2002). Although the ICF stresses environmental and personal factors of health and disability, rehabilitation medicine tends to neglect the spatial and social environment as well as changes over the individual life course (Cott et al, 2007; Jansma et al, 2010). Since the 1990s, the social model of disability has increasingly gained traction. This model places less emphasis on disability as a medical condition and more on exclusionary societal practices that act to disable. First coined by the disabled activist and writer Mike Oliver (1983), the social model has been widely adopted by critical geographers and is the framing of disability we utilize for this paper. Following Chouinard (2010: 242), we define the social model of disability as "the embodied process of becoming disabled through experiences of physical or mental impairment or illness and the negotiation of relations and practices that value able bodies and minds at the expense of others". This approach helps us to look at disability as constructed through societal exclusionary practices.

\section{Biographical disruption and flow}

The stroke literature notes how impairments following stroke can impact adversely on an individual's life course, disrupting and inhibiting the continuance of their 'normal' life as experienced prior to the onset of the illness (Cott et al, 2007; Nanninga et al, 2015a). Bury (1982) defined this experience as one of 'biographical disruption'. He maintained that we can learn much about everyday situations 
and experiences through analyzing the circumstances in which disruption occurs. His work identifies

106 three key features that underpin biographical disruption. Firstly, he points to disruption of the taken

107 for granted assumptions and behaviors that previously characterized an individual's daily life.

108 Attention here focuses on embodied states not previously brought into consciousness and how these

109 are addressed. Secondly, he identifies a disruption of the individual's biography and their sense of

110 self. Thirdly, he refers to the coping mechanisms mobilized in response to the altered state arising

111 from the disruption. Importantly, biographical disruption is not viewed solely as impacting on the

112 individual experiencing the stroke, but also on families and members of a stroke survivor's wider

113 social networks. In the immediate post-stroke period, survivors are likely to focus on their functional

114 impairments, and on recovering from these. In the longer term, where some impairments prove to

115 be enduring, individuals may identify as being chronically ill and/or disabled (see Cott et al, 2007;

116 Nanninga et al, 2015a).

117 Despite being widely accepted and having come to form something of a 'grand narrative' of

118 stroke, Faircloth et al (2004) maintain that the concept of biographical disruption may be too

119 simplistic. Where illness is marked by sudden onset - as in stroke - they argue that lives are not

120 inevitably disrupted, especially where different symbolic significance may be attached to the

121 experience. So while some individuals may indeed find their lives disrupted as a result of a stroke,

122 others may view having a stroke simply as part of their ongoing life narrative, that is, as a different

123 stage of their life embodiment. In this respect stroke survivors will in maintain a coherent sense of

124 the pre- and post-stroke self. In their critique of the notion of biographical disruption Faircloth et al

125 (2004) draw attention to the intersectionality of stroke with the ageing process, co-morbidity, or pre-

126 existing knowledge of the stroke. They posit that these overlaps may result in what they refer to as

127 'biographical flow' in the experiences of a person pre- and post-stroke (p. 242). Adding further

128 complexity to the literature is a study of identity changes following stroke undertaken by Kuenemund

129 et al (2016). In this research the authors found evidence of personal growth following the trauma of

130 stroke and argued that it would be worthwhile to also consider positive changes post-stroke. 
132 offers a useful lens through which to interpret and to understand how people experience their pre-

133 and post-stroke body physically, cognitively, and emotionally. The concepts of biographical flow and

134 disruption also highlight the importance of understanding the temporal dimensions surrounding the

135 disabling conditions of a stroke. While much of the argument about disruption and flow is cast in

136 temporal terms, the specific focus of this article is on how the spatial, in all its manifestations, such

137 as place, environment and landscape, enters into the story. Therefore, our paper seeks to expand

138 understandings of how a therapeutic engagement with the rural landscape may change over time for

139 individual stroke survivors.

140

\section{Understanding rurality in the Dutch context}

142 Our study was conducted in the rural environment of the Northern Netherlands. Our interpretation

143 of rurality draws on Woods' (2012: 3) definition of: "how rural spatial and social relations are

144 constructed, represented, materialized, performed and contested". The rural is a place where

145 aspects of what is commonly regarded as 'natural' in terms of for instance vegetation, animals,

146 rivers, and slopes, are more obviously present. We recognize, of course, that, in most areas these

147 features of rurality are rarely entirely 'natural' but rather are the product of centuries of

148 interventions from factors such as human occupation and agricultural production. In this article, we

149 focus on the 'everyday lives of the rural' which has been identified as one of the key facets of rurality

150 (Halfacree, 2006: 51). The rural setting is appropriate, since it contains a variety of spatial

151 characteristics that, in one way or another, appear to be deepen biographical disruptions or facilitate

152 biographical flows in the lives of stroke survivors.

153 When studying the potentially therapeutic nature of the rural environment, it is important to

154 acknowledge that what is 'rural' and what the rural landscape looks like differs significantly between

155 different countries. The Netherlands is a largely urbanized country, with very high population

156 densities, averaging 498 people per square kilometer. In comparison, the population density of 
157 Belgium is 369; the United Kingdom 265; and Sweden 23 (World Bank, 2013). Even the environment

158 that is classified as rural in the Netherlands can be relatively densely populated, with areas being 159 designated as rural if they have an address density of fewer than 500 people per square kilometer ${ }^{1}$

160 (CBS, 2015). Importantly, 99.6 percent of rural dwellers in the Netherlands are still able to reach a

161 first aid post in a hospital within a 30 minute drive and 53.7 percent are able to reach a hospital

162 within a 10 minute drive (RIVM, 2014). This means that even for those areas defined as rural, acute

163 care is never really that far away.

164 However, in a broader context dominated by neoliberal imperatives, health care services

165 (particularly in rural areas) are typically being reduced and concentrated (Chouinard and Crooks,

166 2008; England et al, 2007). In the Dutch context, austerity measures and cutbacks have led to a

167 concentration of health services in areas of higher population density, resulting in the demise of local

168 village-based services (RIVM, 2014; Gijsen and Poos, 2013). In their stead, healthcare providers, such

169 as general practitioners, physiotherapists, dentists, psychologists, social workers, occupational

170 therapists, as well as surgeons undertaking minor operations previously carried out their duties in

171 local hospitals. However, today they are typically concentrated in larger regional centers. Financial

172 cutbacks are also placing pressure on rehabilitation centers to shorten the duration of expensive in-

173 patient rehabilitation services. The focus is on delivering post discharge care and treatment at home,

174 by a specialized team, as early as possible (see, for example, Mas and Inzitari, 2015; Nanninga et al,

175 2015b). Although these services are potentially enabling for rural dwellers who require them, service

176 concentration is based on the premise that rural dwellers can secure access to them (see Goins et al,

177 2005). Understanding how service concentration is impacting on the lives of rural stroke survivors

178 may be an important aspect of their spatial experience post-stroke.

179

\footnotetext{
${ }^{1}$ the number of addresses within a circle with a one kilometer radius around an address, divided by the surface of the circle (CBS, 2015).
} 
181 This article is part of a larger qualitative study on stroke survivors' experiences of the transition from

182 the rehabilitation unit to the home-setting. Our methodology is informed by approaches to the 183 geographies of disability (Chouinard, 2010; Imrie and Edwards, 2007). That is, we undertook 184 qualitative in-depth interviews designed to give voice to stroke survivors, to understand their experiences over time, and to increase insight into the diversity of their experiences. and rural areas. However, given the neo-liberal imperatives discussed above, we were particularly interested in the experiences of rural dwelling stroke survivors. Hence, in this article, we draw specifically on data collected with those stroke survivors who were living in rural areas in the North of the Netherlands pre-stroke. The data are drawn from semi-structured in-depth interviews with 19

191 stroke survivors, collected in two separate phases. In the first phase (2010-2011), thirteen

192 participants (1-13, Table 1) were approached as a follow-up after they had completed a survey and 193 indicated they were willing to participate in an in-depth interview. Subsequently, in 2011 and 2012,

194 six participants (14-19, Table 1) were interviewed twice, once in the rehabilitation unit and once at

195 home. Participants were recruited by the third author, who was working as a physiotherapist at the

196 stroke rehabilitation unit at the time. All in-depth interviews were conducted at a time and location

197 that was convenient for the participants, and in the presence of a 'significant other' such as a partner

198 or a sibling. During the interviews, the participants were asked to reflect on their current bodies and

199 (expectations about) their lives in the rehabilitation unit, at home and in the community, and to 200 comment on differences in their daily lives pre- and post-stroke. Overall, the interview guides in both 201 phases covered the same questions; however, our learning experiences and the inductive inferences 202 emerging from the first set of interviews were used to refine the questions in the second set of 203 interviews and opened new paths of inquiry.

\footnotetext{
${ }^{2}$ This study was part of a previously published larger study. Given the same methodology was used, parts of this section are taken from Nanninga et al (2015a).
} 
205 for at least one month, and all returned home afterwards. Since we recruited participants through 206 the rehabilitation unit, our sample consists of participants who had suffered a moderate to severe 207 stroke, and were relatively young. Older and fragile stroke survivors more often undertake 208 rehabilitation in a nursing home setting, and survivors of a light stroke are typically discharged home 209 following hospital admission.

All participants were informed about the aims of the study, signed a consent form, and

211 participated voluntarily. Following Dutch ethical review processes, the study was submitted to the 212 Medical Ethical Review Committee of the University Medical Center Groningen. It was exempted 213 from review, which means that the Committee did not identify any ethical problems with the 214 research. The in-depth interviews were digitally recorded, transcribed verbatim, coded and analyzed 215 using Atlas-ti, a software package for qualitative data analysis. Coding and analysis were carried out 216 by the first author and reflected on by the second and last authors. In our analysis, we focused on 217 how the social and material components of the rural landscape created different therapeutic 218 encounters pre- and post-stroke, identifying patterns of biographical flow and disruption. Our 219 approach to the data analysis was both deductive and inductive, enhancing the depth of our analysis 220 (see Thornberg, 2012).

\section{Disruption and flow in rural therapeutic landscape experiences}

Differences between participants

224 Participant characteristics are summarized in Table 1. In our analysis we explored patterns of 225 biographical flow and disruption in the stories of different subgroups of participants. Our analysis did 226 not reveal any significant variations in patterns of disruption and flow arising from differing 227 impairments following the stroke; marital; or employment status. Furthermore, while we had 228 anticipated that age might impact significantly on an individual's experience of disruption and flow 229 (e.g. with greater evidence of flow in later life), the data did not support this expectation. 
230 Interestingly, this runs counter to what some of the existing biographical disruption literature tells us.

231 Our data suggest that it is perhaps too simplistic to assume that greater biographical disruption will

232 be experienced at younger age. This is consistent with Faircloth et al's (2005) findings, that narratives

233 of stroke onset can be characterized by both disruption and flow irrespective of age. For example, for

234 working age stroke survivors, biographical disruption may be experienced in relation to employment.

235 At the same time our data reveals that older stroke survivors can also experience significant

236 biographical disruption to their lives, for instance with regard to hobbies or other forms of social

237 engagement.

238 Furthermore, when looking at time since the onset of a stroke, we found that narratives of

239 disruption dominated the stories of participants who had experienced a stroke more than 24 months

240 prior to the interview. This suggests that disruption is likely to remain dominant within stroke

241 survivors' narratives over time. When considering differences in education, our findings indicated

242 that people with vocational training seemed to cope with the stroke effects relatively well; this may

243 be related to their ability to create practical solutions to everyday problems. Another difference

244 between subgroups was that both married and single men experienced rather more biographical

245 flow than women. For some male participants, this may be linked to their vocational training. We

246 acknowledge that the claims made in the section above are tentative, given the relatively small

247 number of participants.

249 Table 1: Participant Pseudonyms and Characteristics

\begin{tabular}{|c|c|c|c|c|c|c|c|c|}
\hline No & Name & Age & Stroke effects $^{a}$ & Education $^{\mathrm{b}}$ & $\begin{array}{l}\text { Employment } \\
\text { status }\end{array}$ & $\begin{array}{l}\text { Marital } \\
\text { status }\end{array}$ & $\begin{array}{l}\text { Time since } \\
\text { stroke onset } \\
\text { (months) }^{c}\end{array}$ & $\begin{array}{l}\text { Biographical } \\
\text { flow/ } \\
\text { disruption }^{d}\end{array}$ \\
\hline 1 & John & 57 & Motor and cognitive & Vocational & Incapacitated & Single & 10 & $\mathrm{D}$ \\
\hline 2 & Paul & 50 & Motor & Unknown & Working & Single & 17 & $\mathrm{~F}$ \\
\hline $3^{e}$ & Simon & 41 & $\begin{array}{l}\text { Motor and behavioural, } \\
\text { mood, swallowing }\end{array}$ & Higher & Incapacitated & Single & 60 & $\mathrm{D}$ \\
\hline 4 & Tom & 60 & $\begin{array}{l}\text { Motor, cognitive and } \\
\text { speech }\end{array}$ & Vocational & Incapacitated & Married & 47 & $\mathrm{D}$ \\
\hline 5 & Caren & 60 & Motor and cognitive & Higher & $\begin{array}{l}\text { Partly } \\
\text { incapacitated, } \\
\text { partly working }\end{array}$ & Single & 25 & $\mathrm{D}$ \\
\hline
\end{tabular}




\begin{tabular}{|c|c|c|c|c|c|c|c|c|}
\hline 6 & Sam & 40 & $\begin{array}{l}\text { Cognitive, mood, speech, } \\
\text { sight and epilepsy }\end{array}$ & Vocational & Incapacitated & Cohabiting & 23 & $\mathrm{~F}$ \\
\hline 7 & Nina & 47 & Motor, cognitive and sight & Vocational & Incapacitated & Married & 17 & $\mathrm{~F}$ \\
\hline 8 & Violet & 42 & Motor and cognitive & Lower & Incapacitated & Cohabiting & 23 & $\mathrm{D}$ \\
\hline 9 & James & 58 & Cognitive and behavioural & Vocational & Incapacitated & Married & 7 & $\mathrm{~F}$ \\
\hline 10 & Victor & 71 & Motor and speech & Vocational & Pensioner & Married & 19 & $\mathrm{~F}$ \\
\hline 11 & Rose & 53 & Motor and cognitive & Vocational & Unemployed & Married & 33 & $\mathrm{D}$ \\
\hline 12 & Laura & 49 & Motor and cognitive & Lower & Pensioner & Married & 21 & $\mathrm{D}$ \\
\hline $13^{\mathrm{e}}$ & Isa & 48 & Motor and cognitive & Vocational & Incapacitated & Single & 78 & $\mathrm{~F}$ \\
\hline 14 & Kate & 61 & Motor & Lower & Unemployed & Married & 8 & $\mathrm{~F}$ \\
\hline 15 & Henry & 69 & Motor & Higher & Pensioner & Married & 6 & $\mathrm{D}$ \\
\hline 16 & Raymond & 68 & Motor & Higher & Pensioner & Married & 6 & $\mathrm{D}$ \\
\hline 17 & Roy & 66 & Cognitive & Vocational & Pensioner & Single & 6 & $\mathrm{~F}$ \\
\hline $18^{\mathrm{e}}$ & Peter & 46 & Motor and behavioural & Vocational & Incapacitated & Married & 6 & $\mathrm{~F}$ \\
\hline 19 & Ron & 63 & Motor and cognitive & Higher & Pensioner & Married & 6 & $\mathrm{~F}$ \\
\hline
\end{tabular}

${ }^{\mathrm{a}}$ The listed stroke effects were recorded by the rehabilitation clinicians, and these typically coincided with the stories that were discussed during the interviews.

${ }^{b}$ Levels of education: lower - finishing secondary school but no further education; vocational - for example tradesman, care worker; higher - technical college/university educated.

${ }^{c}$ For the participants who were interviewed in round 2, we recorded the time post-stroke at the time of the second interview.

${ }^{d}$ Based on text analysis, we determined whether the story of each participant was dominated by narratives of biographical disruption or flow. This does not mean that participants experiencing flow did not recount any experiences of disruption, and vice versa.

e Used to live in a rural area pre-stroke, and moved to an urban area post-stroke.

\section{Disruption and flow in interactions with things and people in rural space}

Pre-stroke, most of our participants enjoyed engaging with the rural landscape but gave little thought to either the enabling or the potentially disabling aspects of the environment. Faced with a post-stroke body, however, many noted how elements of the physical environment that had previously been negotiated with ease, were now experienced as disabling. Participants revealed how, rather than engaging with, and enjoying the wider rural landscape (e.g. the natural scenery, wildlife ), they now found themselves focusing closely on immediate material objects that had become obstacles to their negotiation of the natural environment. This resulted in experiences of biographical disruption. Victor, for example, explained how he used to enjoy walking or cycling in the rural landscape before his stroke, and had never considered the potential material difficulties involved in moving through this landscape: 
You are never going to be as secure as you were [before the stroke]. I do cycle well, but I have to go through a tunnel at first, and it's very difficult for me to get up [the slope]. So, this hinders me [in going out]. (Victor)

The northern Netherlands is a region that is mostly flat and has no steep hills. Thus, Victor's comment highlights how even relatively minor topographical features can present challenges for the post-stroke body and result in experiences of biographical disruption. A sloping tunnel that facilitated the opening up of the rural landscape in his pre-stroke life, had become a barrier to outdoor activities post-stroke. Sam's experiences revealed another challenge of cycling, namely that of dealing with other traffic participants. Sam ran a nursery garden with his family, and his home and business were located outside a village, in a very quiet rural environment. The quiet traffic situation, together with problems he now experienced with his eyesight, heightened his sense of other traffic participants as 'obstacles':

At first I would cycle and there would be another cyclist coming my way, and I would not see him coming. And when he would be cycling right next to me, and say "hi", I was scared out of my wits, because I would have missed him completely. And now, with a certain way of observing, my eyes to the left and to the right, it's going well. (Sam)

Sam's narrative reveals how he developed a technique to manage the challenges of bicycling poststroke, and participating in traffic situations in particular. He took great pride and pleasure in the fact that he could once again take his five-year-old son on bicycle tours through the rural landscape, which strengthened their bond. This demonstrates how material objects and aspects of the environment are connected to the social landscape. Furthermore, Sam's experiences show how he 
had developed a technique that enabled him to manage his post-stroke body in a way that 298 demonstrates a shift toward biographical flow.

Physical elements of the seasons can also hinder stroke survivors' engagement with the

301 natural environment. These experiences can illuminate the psycho-emotional dimensions of disability which pertain to internalized oppression and negative stereotypes of disability in society (Reeve, 2002). Laura, for example, expressed frustration that her hemiplegic body left her unable to walk outdoors in the winter time, because bad weather made the landscape slippery to negotiate, resulting in a decline of her physical condition. Even when it was not slippery outside, she had to concentrate on her right leg when walking outdoors: When it is slippery, [my partner] does not allow me to go outdoors. [I'm afraid to fall]. It's not nice, that stupid right side [of my body]. I keep dragging [my right leg]. [...] And even when I For Laura, as well as other participants, the change in their embodied state post-stroke rendered artefacts in the rural environment more challenging and the rural space less accessible. Previously

317 taken-for-granted features of the physical landscape were problematic for the post-stroke body. This 318 changed the nature of their experience and shifted their engagement with the rural landscape from 319 one that focused on enjoyment and engagement, to one that was heavily focused on negotiation and 320 the negative emotions associated with highly circumscribed bodily movement ("that stupid right 321 side"). 

previously accessible landscapes disabling. Material objects such as slopes, walls, and tiles become obstacles to any therapeutic encounter with the landscape. This was especially challenging for our participants since they had not perceived these things to be disabling pre-stroke. This reflects the literature on disabling environments and 'ableist spaces', which illustrates how environments are often designed without taking into account the needs and experiences of people with disabilities (Chouinard, 1997; 2006; Crooks et al, 2008a; Imrie and Edwards, 2007; Rattray, 2013).

When looking at how stroke survivors interact with other people in the rural landscape, our participants revealed how their social needs and abilities had changed. In particular, they noted that they felt a continuous need to belong and to be recognized. How this was achieved tended to differ for participants pre-and post-stroke. Pre-stroke, our participants would engage with other villagers in casual conversation, for instance when meeting them in the street or at the local shops. Post-stroke,

334 participants revealed how they tended to avoid potentially difficult social encounters by engaging with people from a distance. Laura, for instance, noted that she would go out with the specific aim of waving at some family members and friends. It gave her a good feeling to go out with a particular purpose rather than "just walking around aimlessly" as she described it.

344 By engaging in social interaction from a distance with, in this case, her partner, Laura illustrated how 345 she had developed a strategy that helped her to feel socially included and part of the community, 346 thus achieving a sense of biographical flow. It seemed that for her, as well as for some other 347 participants, direct conversation with other people could be demanding and hence something to be 
348 avoided where possible. This was most evident where oral communication skills and/or information

349 processing abilities were impaired. The social landscape of rural village dwelling, we suggest, can

350 offer a relatively quiet and unthreatening social space, that can provide opportunities for stroke

351 survivors to engage in social interaction from a distance; in doing so it enables them to feel 352 acknowledged and included without the pressure of close physical engagement. These findings 353 reinforce Jones and Curtis' (2010) Australian study on rural-dwelling survivors of a Traumatic Brain 354 Injury (TBI), where the rural, offering a potentially quiet social environment, was found to actually 355 suit participants. These findings reinforce the notion of the rural as an enabling social space (Walsh 356 and O'Shea, 2008), as well afford support to the claim that informal practices in rural communities 357 can help to reduce experiences of social exclusion (Walsh et al, 2014). However, we acknowledge 358 that the rural can also be a space of social exclusion. Parr et al (2004), in her study with people with 359 mental health problems in the UK, for example, noted that the social environment in rural areas can 360 be characterized by both social inclusion and social exclusion. The rural social environment, they 361 maintained, can sometimes be experienced as an unnerving space, which can be difficult to 362 'navigate' in social terms, and where disabled bodies are stigmatized. Similarly, stroke survivors, can 363 experience social exclusion based on a lack of understanding of their disabling conditions by others in 364 their social environment (Crooks et al, 2008b; Nanninga et al, 2015a).

Disruption and flow in interactions with rural gardens and nature

367 When looking at participants' relationships with the rural landscape, stories encompassing 368 complexity and change in therapeutic and disabling landscape experiences emerged. In the 369 Netherlands, rural gardens are generally significantly larger than those situated in urban areas, and 370 are one of the reasons why people choose to live in a rural area. Gardens thus form an important 371 part of people's experiences of rural dwelling and green space, and are important to consider in the 372 context of the rural experience of stroke. Many participants spoke of how, pre-stroke, they had 373 enjoyed working in their gardens, but that this had changed. Take Henry's case: 
H: I do mow the lawn. We have a sizeable piece of grassland, with these precise little corners that you have to do. The first time I did it [after the stroke], I did it in three turns. [...] It's still tiring, but I can do it now. And when I know, I'm going to mow the lawn, I don't do [another exercise]. But it's like, I walk in the garden, and I see all the stuff I'd like to do, but I can't get around to doing it yet. [...] It's my balance, when weeding, you have to get down and up

As a gardener, Henry experienced the garden in a different way pre-and post-stroke. On the one hand, the things he can still do in his garden, such as mowing the lawn, give him a sense of achievement, so contribute to his experience of the garden as a therapeutic place. On the other hand, his story is illustrative of the frustration people can feel post-stroke, when they want to engage in an activity they used to enjoy, but can no longer do so. This loss of place - in Henry's case his interaction with the flower beds - can affect how participants feel about their garden. His story

390 illustrates how the socio-spatial disruptions experienced by the post-stroke body can change an individual's relationship with those places from which people previously derived therapeutic enjoyment. Such findings run counter to those discussed in Jones and Curtin's (2010) work, where stories of disruption such as recounted by Henry, were largely absent. Rather, participants expressed

394 a strong rural identity and found solace in their attachment to a rural idyll, centered around a 395 peaceful and quiet environment. Importantly, as distinct from our study, Jones and Curtis' (2010) 396 work presented a single 'in the moment' account that did not attend to how the experiences of a 397 stroke survivor may change over time.

398 Other participants in our study expressed experiences of disruption from a range of other 399 rural landscapes beyond the garden. In the Dutch context, a specific feature of the rural concerns 
400

401

402

403

404

405

406

407

408

409

410

411

412

413 .

coasts and lakes. Simon's narrative, for example, revealed a sense of biographical disruption from his favorite activity of sailing. He particularly enjoyed the challenge of curbing the natural environment of the sea. Post-stroke his inability to continue sailing was manifested through a narrative of biographical disruption:

I don't have any hobbies anymore, everything takes so much energy. And sailing, [my] sailing boat, I sold it. I tried, but I can't do it anymore. It is difficult. And the most difficult thing for me was, the boat was in [sea port on the Waddensea]. And normally we would go to [another port on the Waddensea] to get an ice cream. My sister was here on Saturday, and she took me where I used to live, and I enjoyed that, to the Waddensea. (Simon)

In returning to the sea shore, Simon sought to re-incorporate his therapeutic engagement with the landscape through the sensory rather than the physical experience: watching the width of the sea from the dyke, smelling the seaweed and eating an ice cream in the restaurant on the seafront. Laura, in contrast, sought to re-incorporate a physical and therapeutic engagement with the canals and lakes close to her home, but struggled to achieve this:

.


427 Laura's strong connection to canoeing was a key theme in her narrative. This was expressed both 428 through her dialogue and through her emotions. She indicated that while she wanted to enjoy the 429 therapeutic benefits of canoeing again, she had not come to terms with the alternative 'solution' to 430 participating in this activity. The notion of taking a less active role in the canoe and perhaps reading a 431 book or watching birds while still immersed in the quiet, natural environment was not palatable to 432 Laura. Her narrative reveals that in the absence of being able to undertake the repetitive movements 433 of paddling and engaging in the physicality of canoeing she felt out of control in the natural 434 landscape. A space and an activity undertaken in this space that were previously therapeutic were no 435 longer experienced as such. Whilst not the core focus of our paper,Simon and Laura's stories also 436 highlight the benefits of 'blue space' as therapeutic landscapes in that they may also provide physical 437 and emotional restoration (Korpela et al, 2010; Völker and Kistemann, 2011; 2013). Nina, who experienced a stroke as a complication with a hip surgery, revealed a more positive narrative. She had struggled for years with a deteriorating ability to walk, especially since hiking used to be a pre-arthritic hip and pre-stroke leisure activity that she and her family vastly 441 enjoyed. Following a hip replacement, Nina managed to regain her pre-stroke and pre-surgery 442 physical condition, enabling her to take up hiking again around the rural living environment 443 proximate to where she lived. She commented on how much this meant for her: $\mathrm{N}$ : Walking is going really well, fantastic. I walk about ten kilometers per day, it's great.

446 I: You don't know what's happening to you. [laughter]

$447 \quad \mathrm{~N}$ : No, really. We say it to each other like ten times on the way, like this is to special, so $448 \quad$ special.

$449 \quad$ I: And no limitations? $\mathrm{N}$ : No, really. That's the great thing, because I have not been able to do this for years. My mum lives in the next village, more than four kilometers from here. And now, well the first 
time I did not walk all the way to [my mum's village] of course. And the first time I did walk there, I had to rest on a bench on the way. And now I walk there, just like that. And I even walk back. The first time you had to call like, well I'm there, please come and pick me up. And now I walk back home, that's fantastic. And we go on long walks in the forest, and we go everywhere, it's great. (Nina)

Nina's narrative is one of biographical flow, in which she was able to regain much of her former life following a period of disruption resulting from her hip problems and stroke. After this period of disruption, it might even be argued that she experienced a 'biographical peak'. By this we mean that following a long period of physical disability, Nina's regaining an ability to walk significant distances was experienced as particularly enabling.

\section{Barriers in interacting with rural health care services}

465 As well as being a material, social and natural environment, the rural landscape is also a setting in 466 which stroke survivors have to negotiate and access services, including health care services. Our 467 participants' experiences of accessing and using these services were often framed in terms of 468 barriers which can be interpreted through the notion of biographical disruption. This was, in part, related to issues of transportation. In the case of stroke survivors, this is an important issue in the Netherlands as stroke survivors are, by default, banned from driving for at least six months post-

471 stroke. Given that rural areas are generally not well-serviced by public transport, rural stroke 472 survivors are often dependent on being driven by significant others or reliant on professional taxi 473 drivers to take them to health care services that they are unable to reach by foot, bicycle or mobility 474 scooter. Raymond, for instance, explained how he had become dependent on his wife, since being 475 banned from driving: 

not allowed to drive for another three months. So that makes you dependent on others to drive you around.

Stroke survivors' ability to drive pre-stroke was typically self-evident, meaning our participants were aspect of the rural environment. health care services. James, for instance, had to travel three times a week for outpatient treatment: Monday, Wednesday and Thursday. [...]

Whilst transport by taxi would be covered by health insurance, a single journey by taxi to a I: How long does it take you to get there? J: By taxi, you mean? That's about 45 minutes [one-way].

497 thus find themselves spending a significant part of their week on travelling to (and engaging in) 498 outpatient treatment.

499 As well as health care, other services, such as shops and transport were vital for enabling our 500 participants to continue living in a rural area. Some participants realized that they would be unable 501 to regain a sense of biographical flow in a rural setting, and had therefore decided to move away. 502 Peter described how the remote nature of his former rural home had compelled him and his partner 
503

to move to an urban location. Although he had anticipated having to move into town in his later life

504 (i.e. post-retirement), the disabling experiences of the rural landscape post-stroke led him to 505 advance this decision:

506

507

508

509

Hence, rather than living in what Peter had come to experience as a disabling environment, he chose to move to an area where he had easier access to shops and services. Peter's decision illustrates how he reorganized his life so that his lived experience was not manifest in biographical disruption, but in biographical flow. Again this narrative runs counter to that of other research on disability and rurality that suggests that the attachment to the rural social and physical landscape, and the desire to preserve a rural identity, outweigh restrictions in terms of access to services such as healthcare, shops and public transport (Jones and Curtis, 2010).

\section{Concluding comments: Towards bio-geographical disruption and flow}

521 Drawing on our work with rural-dwelling stroke survivors, we have explored how the biographical 522 disruption and flow that occurs as a result of stroke impacts on the therapeutic experience of the 523 person-landscape encounter in the Northern Netherlands. In particular, we have highlighted the 524 importance of bringing together the dimensions of time and place in studying disabled people's 525 everyday lives. More specifically, our findings demonstrate how material, social, natural and healthcare environments that have previously been experienced as enabling, easily negotiable and 
versa). Furthermore, they show how stroke survivors experience biographical flow in engaging with some natural and social rural places.

Within these narratives of stroke and stroke survival, the spatial relationship between the

pre- and post-stroke body and the (rural) environment is crucial. We thus suggest that rather utilizing the terms 'biographical flow' and 'biographical disruption', we should instead engage the notions of 'bio-geo-graphical flow' and 'bio-geo-graphical disruption'. For us, the inclusion of the -geo-graphical perspective, focuses particular attention on the extent to which relational experiences of space/place are disrupted by changes in the life course arising from disability as well as and on how taken for granted embodied states have to be renegotiated at any other place anew. A bio-geo-graphical perspective thus has the potential to explain: 1 ) how the embodied experiences of places that were experienced as therapeutic pre-stroke, are renegotiated and can become ambiguous post-stroke; 2)

539 how stroke survivors actively seek to (re)gain certain abilities that will enable them to access 'lost' 540 and 'new' activities and places. This suggests that whilst some stroke survivors may initially 541 experience bio-geo-graphical disruption, there is a determination to return to a position of bio-geo542 graphical flow, or to create a renewed sense of bio-geo-graphical flow. The concepts of bio-geo-graphical disruption and flow are not restricted to either rural areas,

544 or to stroke survivors, since they engage with the interactions between people who become disabled 545 and places over time. At a more general level, the experiences of our disabled participants also 546 illuminate how they sometimes struggled to move and live in spaces that are essentially 'ableist', 547 reinforcing the critical work emerging from within disability geography (Chouinard, 2006). Our 548 findings thus provide a compelling case for re-thinking the medical model which continues to 549 dominate rehabilitation research and practice and instead working to enhance a more embodied and 550 robust social model of disability.

552 In terms of therapeutic landscapes, we reflected on the limited engagement with the temporal 553 nature of the therapeutic landscape encounter to date. Drawing on the concepts of bio-geo-graphical 
554 flow and bio-geo-graphical disruption, we suggest, provides a framework through which we can 555 begin to understand the importance of time and life-course in shaping landscape experiences. Taking 556 a temporal lens to the experiences of stroke survivors has enabled us to reveal how an individual's 557 construction of a therapeutic landscape can and does, change over time. In the case of rural stroke 558 survivors we have illustrated how the relational engagement with some rural environments can 559 change from being therapeutic and enabling landscapes to ones that are disabling and filled with 560 tension, and vice versa. We also suggest that questions about the palliative or longer-term healing 561 effects of therapeutic landscapes (Willis, 2009) are complex, and need to be understood in relation to 562 individualized experiences and contexts over time. However, the participants' stories also reinforced 563 the importance of understanding the relational nature of therapeutic landscapes (Conradson, 2005), 564 as the individual's relational experience of the physical and social landscape jostle against each other 565 in ways that have the potential to cause a friction that did not occur pre-stroke. Nevertheless, our 566 participants' stories reveal that despite the loss stroke survivors experience on all those domains, 567 they may still experience and gain benefit from the beauty of the rural landscape (see Price et al, 568 2012).

$569 \quad$ Like all research, our study has limitations. Firstly, it did not set out to explore biographical 570 flow and/or disruption and hence our interview themes were not specifically designed to elicit 571 experiences of flow or disruption. Rather, these concepts emerged through our data-analysis. 572 Secondly, we did not attempt to achieve theoretical sampling or data-saturation for subgroups of 573 rural stroke survivors, for example, by age, gender, education and ethnicity, as well as place of 574 residence (urban-rural), place of origin and health status pre-stroke. Hence, we cannot draw 575 definitive conclusions about differences between groups, though as we have indicated, some 576 differences between groups of participants were evident and this warrants further exploration. 577 Thirdly, in this study we were unable to follow up with participants whose stories were dominated by 578 narratives of bio-geo-graphical disruption to see if, over time, they may have returned to a narrative 579 of bio-geo-graphical flow (or vice versa). This too is deserving of further enquiry. Hence, in relation to 
580 the above limitations, we see considerable scope for further research - not just among different 581 subgroups of stroke survivors, but also amongst people experiencing other types of chronic ill-health.

582 Additional research has the potential to increase our understanding of how bio-geo-graphical flow 583 and bio-geo-graphical disruption may be experienced by different groups of people, in different 584 places with different acquired impairments. Finally, we acknowledge that using in-depth interviews 585 meant that those whose speech and/or language were impaired, and who found it difficult to 586 articulate their stories orally, were underrepresented in our study. Whilst efforts were made to 587 include those who had difficulties expressing their stories through encouraging partners to help, we 588 acknowledge that this strategy has limitations. For future studies, it may be useful to think of 589 adopting visual and/or interactive methods, such as observation, mental mapping, photo elicitation, 590 and walking interviews, to capture the perceptions and practices of people experiencing different 591 impairments. Whilst our methodology enabled us to give voice to our participants, it might also be 592 worth considering the ways in which co-production of this knowledge can be enhanced in the future 593 (see Chouinard, 2010).

594 As we form an interdisciplinary team, comprising geographers, rehabilitation researchers and 595 practitioners, the findings from our study have informed rehabilitation practice. For instance, a 596 coaching program has been established for stroke survivors who have returned home. The purpose 597 of the program is to support the home-making process at places where stroke-survivors wish to 598 (inter)act, such as everyday rural landscapes. Further research is needed to improve the lives of 599 stroke survivors and will contribute to further exploring how re-embodiment for stroke survivors 600 needs to be considered a life long project. This is of particular importance given stroke survivors need 601 to re-engage with both familiar and non-familiar place in rural and urban landscapes. These places 602 contain diverse human and non-human actors that need to be tackled consciously every day anew. 603 Both stroke rehabilitation practice and research appear to have neglected this important aspect of 604 stroke survivors' engagement with the landscape (Cott et al, 2007). Therefore, adding the prefix geo 
605 to the theoretical repertoire of the biographical disruption literature may help both rehabilitation

606 practitioners and researchers to acknowledge the importance of place in stroke care.

607

608 References

609 BHF, 2014. Stroke. Your quick guide. http://www.bhf.org. Accessed 07-04-2016. London, British

610 Heart Foundation.

611 Bury, M., 1982. Chronic illness as biographical disruption. Sociology of Health \& Illness 4, 167-182.

612 doi: 10.1111/1467-9566.ep11339939.

613 Carpiano, R.M., 2006. Toward a neighborhood resource-based theory of social capital for health: Can

614 Bourdieu and sociology help? Social Science \& Medicine 62, 165-175. doi:

$615 \quad$ 10.1016/j.socscimed.2005.05.020.

616 Cattell V., Dines N., Gesler W., Curtis, S., 2008. Mingling, observing, and lingering: everyday public

617 spaces and their implications for well-being and social relations. Health \& Place 14, 544-561. doi:

618 10.1016/j.healthplace.2007.10.007.

619 CBS, 2015. Stedelijkheid (van een gebied) [Urbanity (of an area)]. www.cbs.nl. Accessed 29-03-2016.

620 The Hague, Centraal Bureau voor de Statistiek [Central Statistics Bureau].

621 CBS, 2014. Beroerte [Stroke prevalence]. http://statline.cbs.nl/statweb/. Accessed 19-05-2015. The

622 Hague, Centraal Bureau voor de Statistiek [Central Statistics Bureau].

623 Chouinard, V., 2006. On the dialectics of differencing: disabled women, the state and housing issues.

624 Gender, Place \& Culture 13, 401-417. doi: 10.1080/09663690600808528.

625 Chouinard, V., 2010. Impairment and disability. In: Brown, T, McLafferty, S., Moon, G. (Eds.), A 626 companion to health and medical geography. Oxford, Wiley-Blackwell (pp. 242-258). doi: $627 \quad 10.1111 /$ b.9781405170031.2010.00015.x.

628 Chouinard, V., Crooks, V.A., 2008. Negotiating neoliberal environments in British Columbia and 629 Ontario, Canada: restructuring of state - voluntary sector relations and disability organizations' 
630 struggles to survive. Environment and Planning C. Government \& Policy 26, 173-190. doi:

631 10.1068/c0502r.

632 Conradson, D., 2005. Landscape, care and the relational self: therapeutic encounters in rural England.

633 Health \& Place 11, 337-348. doi: 10.1016/j.healthplace.2005.02.004.

634 Cott, C.A., Wiles, R., Devitt, R., 2007. Continuity, transition and participation: preparing clients for life

635 in the community post-stroke. Disability \& Rehabilitation 29, 1566-1574. doi:

$636 \quad 10.1080 / 09638280701618588$.

637 Crooks, V.A., Dorn, M.L., Wilton, R.D., 2008a. Emerging scholarship in the geographies of disability.

638 Health \& Place 14, 883-888. doi: 10.1016/j.healthplace.2007.10.013.

639 Crooks, V.A., Chouinard, V., Wilton, R., 2008b. Understanding, embracing and rejecting: women's 640 negotiations of disability constructions and categorizations after becoming chronically ill. Social 641 Science \& Medicine 67, 1837-1846. doi: 10.1016/j.socscimed.2008.07.025.

642 Curtis, S., Gesler, W., Wood, V., Spencer, I., Mason, J., Close, H., Reilly, J., 2013. Compassionate 643 containment? Balancing technical safety and therapy in the design of psychiatric wards. Social 644 Science \& Medicine 97, 201-209. doi: 10.1016/j.socscimed.2013.06.015.

645 Duff, C., 2012. Exploring the role of 'enabling places' in promoting recovery from mental illness: a 646 qualitative test of a relational model. Health \& Place 18, 1388-1395. doi: 647 10.1016/j.healthplace.2012.07.003.

648 England, K., Eakin, J., Gastaldo, D., McKeever, P., 2007. Neoliberalizing home care: managed 649 competition and restructuring home care in Ontario. In: England, K., Ward, K. (eds.), 650 Neoliberalization. States, networks, peoples. Malden, Blackwell (pp. 169-194). doi: $651 \quad$ 10.1002/9780470712801.ch7.

652 Faircloth, C.A., Boylstein, C., Rittman, M., Gubrium, J., 2005. Constructing the stroke: sudden-onset 653 narratives of stroke survivors. Qualitative Health Research 15, 928-941. 654 doi: 10.1177/1049732305277842. 
655 Faircloth, C.A., Boylstein, C., Rittman, M., Young, M.E., Gubrium, J., 2004. Sudden illness and 656 biographical flow in narratives of stroke recovery. Sociology of Health \& Illness 26, 242-261. doi: 657 10.1111/j.1467-9566.2004.00388.x.

658 Gesler, W.M., 1992. Therapeutic landscapes: medical issues in light of the new cultural geography. 659 Social Science \& Medicine 34, 735-746. doi: 10.1016/0277-9536(92)90360-3.

660 Gijsen, R., Poos, M.J.J.C., 2013. Wat zijn de trends in zorggebruik? [What are the trends in care use?]. 661 National Institute for Public Health and the Environment (RIVM), Bilthoven.

662 Goins, R.T., Williams, K.A., Carter, M.W., Spencer, S.M., Solovieva, T., 2005. Perceived barriers to 663 health care access among rural older adults: a qualitative study. The Journal of Rural Health 21, 206664 213. doi: 10.1111/j.1748-0361.2005.tb00084.x.

665 Halfacree, K., 2006. Rural space: constructing a three-fold architecture. In: Cloke, P., Marsden, T., 666 Mooney, P. (eds), Handbook of rural studies. London, Sage (pp. 44-62). doi: $667 \quad 10.4135 / 9781848608016 . n 4$.

668 Hartig, T., Staats, H., 2006. The need for psychological restoration as a determinant of environmental 669 preferences. Journal of Environmental Psychology 26, 215-226. doi: 10.1016/j.jenvp.2006.07.007.

670 Imrie, R., Edwards, C., 2007. The geographies of disability: reflections on the development of a sub671 discipline. Geography Compass 1, 623-640. doi: 10.1111/j.1749-8198.2007.00032.x.

672 Jansma, F.I., van Twillert, S., Postema, K., Sanderman, R., Lettinga, A.T., 2010. Physical and 673 rehabilitation medicine and self-management education: A comparative analysis of two approaches. 674 Journal of Rehabilitation Medicine 42(9), 808-814. doi: 10.2340/16501977-0606.

675 Jones, J., Curtin, M., 2010. Traumatic Brain Injury, participation, and rural identity. Qualitative Health 676 Research 20, 942-951. doi: 10.1177/1049732310365501.

677 Kaplan, S., 1995. The restorative benefits of nature: Toward an integrative framework. Journal of 678 Environmental Psychology 15, 169-182. doi: 10.1016/0272-4944(95)90001-2. 
679 Korpela, K.M., Ylén, M., Tyrväinen, L., Silvennoinen, H., 2010. Favorite green, waterside and urban 680 environments, restorative experiences and perceived health in Finland. Health Promotion 681 International 25, 200-209. doi: 10.1093/heapro/daq007.

682 Korpela, K.M., Ylén, M., Tyrväinen, L., Silvennoinen, H., 2008. Determinants of restorative 683 experiences in everyday favorite places. Health \& Place 14, 636-652. doi: 684 10.1016/j.healthplace.2007.10.008.

685 Kuenemund, A., Zwick, S., Rief, W., Exner, C., 2016. (Re-)defining the self - Enhanced posttraumatic 686 growth and event centrality in stroke survivors: a mixed-method approach and control comparison 687 study. Journal of Health Psychology 21(5), 679-689. doi: 10.1177/1359105314535457.

688 Mas, M.A., Inzitari, M., 2015. A critical review of Early Supported Discharge for stroke patients: from 689 evidence to implementation into practice. International Journal of Stroke 10, 7-12. 690 doi:10.1111/j.1747-4949.2012.00950.x.

691 Masuda, J., Crabtree, A., 2010. Environmental justice in the therapeutic inner city. Health \& Place 16, 692 656-665. doi: 10.1016/j.healthplace.2010.02.003.

693 Milligan, C., Bingley, A., 2007. Restorative places or scary spaces? The impact of woodland on the 694 mental well-being of young adults. Health \& Place 13, 799-811. doi: 695 10.1016/j.healthplace.2007.01.005.

696 Milligan, C., Gatrell, A., Bingley, A., 2004. 'Cultivating health': therapeutic landscapes and older 697 people in northern England. Social Science \& Medicine 58, 1781-1793. doi: 10.1016/S0277$6989536(03) 00397-6$.

699 Milligan, C., Payne, S., Bingley, A., Cockshott, Z., 2015. Place and wellbeing: shedding light on activity 700 interventions for older men. Ageing \& Society 35, 129-149. doi: 10.1017/S0144686X13000494.

701 Moore, A., Carter, B., Hunt, A., Sheikh, K., 2013. 'I am closer to this place' - Space, place and notions 702 of home in lived experiences of hospice day care. Health \& Place 19, 151-158. doi: 703 10.1016/j.healthplace.2012.11.002. 
704 Nanninga, C.S., Meijering, L., Schönherr, M.C., Postema, K., Lettinga, A.T., 2015a. Place attachment in

705 stroke rehabilitation: a transdisciplinary encounter between cultural geography, environmental 706 psychology and rehabilitation medicine. Disability \& Rehabilitation 37(13), 1125-1134. 707 doi:10.3109/09638288.2014.955136.

708 Nanninga, C.S., Postema, K., Schonherr, M.C., van Twillert, S., Lettinga, A.T., 2015b. Combined clinical 709 and home rehabilitation: a case report of an integrated knowledge-to-action study in a Dutch 710 rehabilitation stroke unit. Physical Therapy 95(4), 558-567. doi: 10.2522/ptj.20130495

711 Oliver, M., 1983. Social work with disabled people. Basingstoke, Palgrave Macmillan.

712 Parr, H., Philo, C., Burns, N., 2004. Social geographies of rural mental health: experiencing inclusions 713 and exclusions. Transactions 29, 401-419. doi: 10.1111/j.0020-2754.2004.00138.x.

714 Price, P., Kinghorn, J., Patrick, R., Cardell, B., 2012. "Still there is beauty": one man's resilient 715 adaptation to stroke. Scandinavian Journal of Occupational Therapy 9, 111-117. doi: $716 \quad 10.3109 / 11038128.2010 .519402$.

717 Rattray, N.A., 2013. Contesting Urban Space and Disability in Highland Ecuador. City \& Society 25, 718 25-46. doi: 10.1111/ciso.12008.

719 Reeve, D., 2002. Negotiating psycho-emotional dimensions of disability and their influence on 720 identity constructions. Disability \& Society 17, 493-508. doi: 10.1080/09687590220148487.

721 RIVM, 2014. Volksgezondheid Toekomst Verkenning, Nationaal Kompas Volksgezondheid, versie 4.17 722 [Exploring Future Public Health, National Public Health Compass, version 4.17]. Bilthoven, National 723 Institute for Public Health and the Environment.

724 Stucki, G., Ewert, T., Cieza, A., 2002. Value and application of the ICF in rehabilitation medicine. 725 Disability \& Rehabilitation 24, 932-928. doi: 10.1080/09638280210148594.

726 Thornberg, R., 2012. Informed grounded theory. Scandinavian Journal of Educational Research 56, 727 243-259. doi: 10.1080/00313831.2011.581686.

728 Ulrich, R.S., 1984. View through a window may influence recovery from surgery. Science 224, 420729 421. doi: $10.1126 /$ science.6143402. 
Ulrich, R.S., 1983. Aesthetic and affective response to natural environment. Human Behavior and

731 Environment 6, 85-125. doi: 10.1007/978-1-4613-3539-94.

732 Völker, S., Kistemann, T., 2011. The impact of blue space on human health and well-being -

733 Salutogenetic health effects of inland surface waters: a review. International Journal of Hygiene and

734 Environmental Health 214, 449-460. doi: 10.1016/j.ijheh.2011.05.001.

735 Völker, S., Kistemann, T., 2013. Reprint of: “I'm always entirely happy when I'm here!” Urban blue

736 enhancing human health and well-being in Cologne and Düsseldorf, Germany. Social Science \&

737 Medicine 91, 141-152. doi: 10.1016/j.socscimed.2012.09.047.

738 Wakefield, S., McMullan, C., 2005. Healing in places of decline: (re)imagining everyday landscapes in

739 Hamilton, Ontario. Health \& Place 11. doi: 10.1016/j.healthplace.2004.05.001.

740 Walsh, K., O'Shea, E., 2008. Responding to rural social care needs: older people empowering 741 themselves, others and their community. Health \& Place 14, 795-805. doi: $742 \quad$ 10.1016/j.healthplace.2007.12.006.

743 Walsh, K., O'Shea, E., Scharf, T., Shucksmith, M., 2014. Exploring the impact of informal practices on 744 social exclusion and age-friendliness for older people in rural communities. Journal of Community \& 745 Applied Social Psychology 24, 37-49. doi: 10.1002/casp.2176.

746 Wiles, J.L., Allen, R.S., 2010. Embodied ageing in place: what does it mean to grow old? In: Chouinard, 747 V., Hall, E., Wilton, R. (eds), Towards enabling geographies: 'disabled' bodies and minds in society 748 and space (pp. 217-235). Farnham, Ashgate.

749 Williams, A., 2010. Spiritual therapeutic landscapes and healing: A case study of St. Anne de Beaupre,

750 Quebec, Canada. Social Science \& Medicine 70, 1633-1640. doi: 10.1016/j.socscimed.2010.01.012.

751 Williams, A., 2002. Changing geographies of care: employing the concept of therapeutic landscapes 752 as a framework in examining home space. Social Science \& Medicine 55, 141-154. doi: 753 10.1016/S0277-9536(01)00209-X.

754 Willis, A., 2009. Restoring the self, restoring place: healing through grief in everyday places. Emotion, 755 Space \& Society 2, 86-91. doi: 10.1016/j.emospa.2009.09.001. 
756 Wood, V.J., Curtis, S.E., Gesler, W., Spencer, I.H., Close, H.J., Mason, J., Reilly, J.G., 2013. Creating

757 'therapeutic landscapes' for mental health carers in impatient settings: a dynamic perspective on

758 permeability and inclusivity. Social Science \& Medicine 91, 122-129. doi:

$759 \quad$ 10.1016/j.socscimed.2012.09.045.

760 Woods, M. 2012. New directions in rural studies? Journal of Rural Studies 28, 1-4. doi:

$761 \quad$ 10.1016/j.jrurstud.2011.12.002.

762 World Bank, 2013. Population density (people per sq.km. of land area).

763 http://data.worldbank.org/indicator/EN.POP.DENST/. Accessed 14-06-2015. 